\title{
TOWARDS A STRATEGIC CLOUD COMPUTING FRAMEWORK: A SOUTH AFRICAN CONTEXT
}

\author{
Andrian Wilby Twala ${ }^{1}$ and Ray M Kekwaletswe ${ }^{2}$ \\ ${ }^{1}$ Graduate School of Business Leadership, University of South Africa, Midrand, South Africa \\ ${ }^{2}$ School of Economic and Business Sciences, University of the Witwatersrand \\ Johannesburg, South Africa
}

\begin{abstract}
This paper covers the current research about cloud computing in the context of South African information technology professionals. The main question is how should cloud computing be strategically adopted and used sensitively to the South African context. In this paper, the research argument is that, there is a need for a framework that would assist to strategically adopt and use cloud computing in a uniformed and coordinated manner. To help understand the adoption and use of cloud computing, the stakeholder theory (Freeman, 1984) and contingency theory (Blanton, Watson, \& Moody, 1992) are used as research lenses. This study follows an interpretivism philosophy. The adoption and use of cloud computing will be understood through interviews. The findings from this paper proposed a strategic cloud computing framework that will provide guidance for adoption and use of cloud computing in general. The framework will be analysed based on cloud computing factors, stakeholders, and contingency variables.
\end{abstract}

\section{KEYWORDS}

Cloud Computing, Strategic Framework, South Africa, Stakeholders, Contingency Theory

\section{INTRODUCTION}

Cloud computer is an internet based computing in which users can share information technology resources in a secure and efficient system(Hayes, 2008). In South Africa, organizations are faced with the challenges of mounting costs in keeping the existing hardware and software. Researchers such as (Varia, 2010; Chang, Walters and Wills, 2011) agrees that, cloud computing offers benefits such as, fast provisioning of hardware space, reduced costs for hardware and software, high availability, virtualization, data protection and sharing resources. Cloud computing is defined as the delivery of information technology resources or service via the internet (Mell \& Grance, 2011). The cloud computing model is delivered to organization as pay as you use, where organization consume resources via the internet that are provided by the cloud service provider with guarantees offered via service level agreements (SLA) (Yang and Tate, 2009). South African organizations can benefit from a technology such as cloud computing, where they can leverage on its ability to offer a flexible resource that is scalable to the needs of the organization, which are accessible from anywhere at whatever time. This paper uses the stakeholder theory and contingency theory to understand, how should cloud computing be strategically adopted and used sensitive to the South African context. The paper conceptualizes a strategic cloud-computing framework in the context of South African information technology professionals. The next section discusses the theoretical foundations.

\section{THOERETICAL FOUNDATIONS}

This section discusses the theories that grounded this study. This study underpinning by theories of stakeholder theory by Freeman (1984) and contingency theory (Blanton, Watson, \& Moody, 1992). 


\subsection{Stakeholder Theory}

Stakeholder theory is viewed as a tool for understanding the relation between management, stakeholders and the organization's behavior towards the stakeholders (Freeman,1984). The stakeholder theory is widely used in previous studies, including information systems and management studies. According to Freeman (1984) stakeholders are defined as "any group or individual that can affect or is affected by the achievements of the organization's objectives". Clarkson (1995) defines stakeholders as "persons or groups that have claimed ownership, rights, or interests in a corporation and its activities, past, present, or future." The stakeholder theory asks managers to communicate the value that is being created when stakeholders working together. The focus of the stakeholder theory is to answer two main questions(Freeman, 1984). The first question asks is, "What is the purpose of the firm?" This encourages leaders of an organization to communicate the value that is being created by stakeholders working together, to produce outstanding performance. The second question asks is, "What responsibility does management have to stakeholders? "The stakeholder theory was originally presented as a map with the firm in the center of the wheel and the stakeholders around the rim. The stakeholder map is presented in figure 1. According to figure 1, there are various stakeholders influencing the firm when adopting and using innovation.

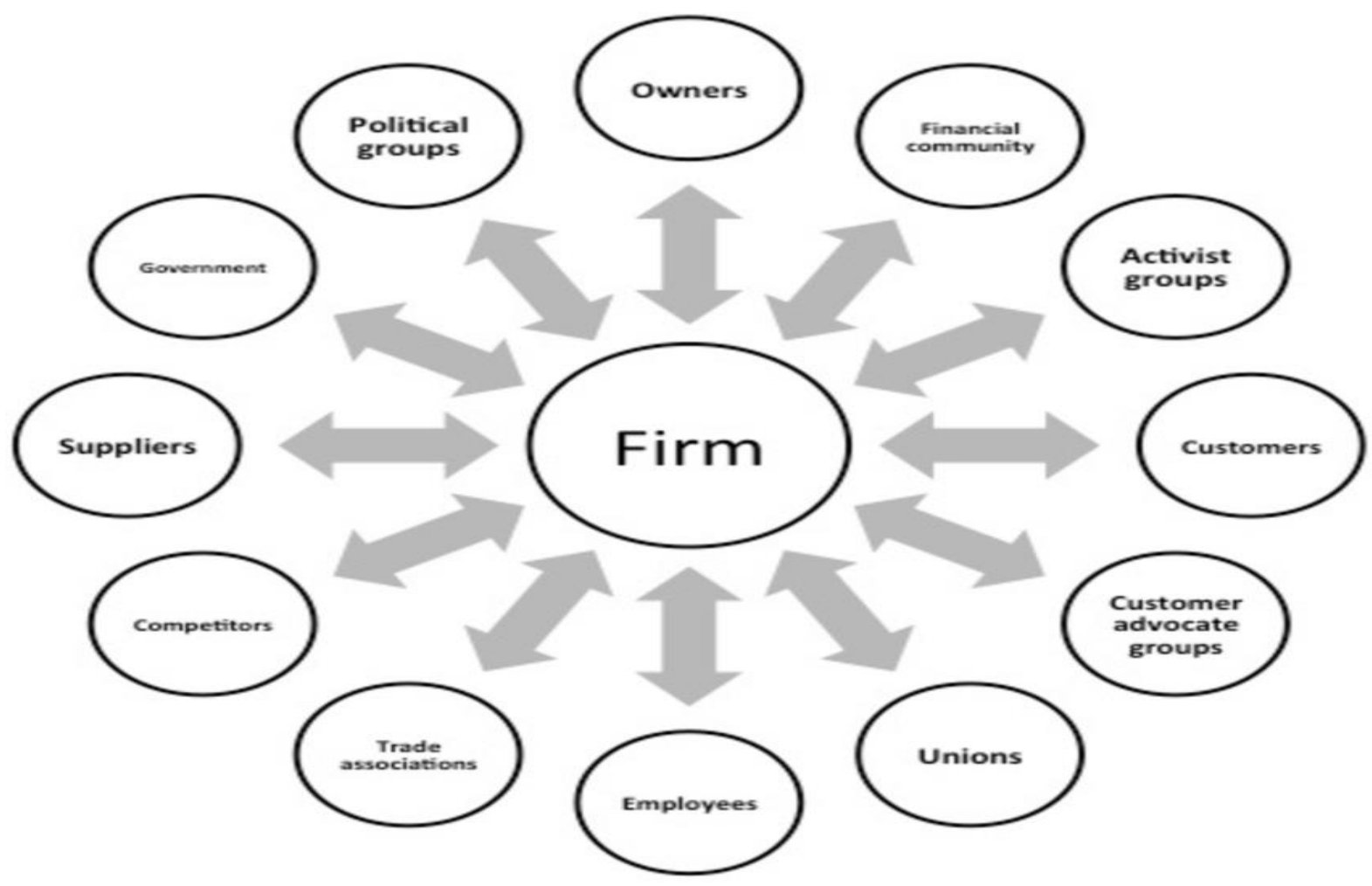

Figure 1. Stakeholder Map (Freeman, 1984)

\subsection{Contingency Theory}

The contingency theory is used to view organizations as a whole. The contingency theory assumptions are that there is no one best way of organizing. According to Donaldson (2001), contingency theory is defined as "a variable that moderates the effect of organizational characteristics on organizational performance." The basis of contingency theory is that organizational performance is dependent on the organizational characteristics such as a structure that reflects the situation of an organization (Donaldson, 2001). The organizational performance depends on the matching fitted between organizational structure and the contingencies. The key contingencies that have been suggested are environmental uncertainty, organizational 
strategy, and technology. The organizations are seeking to design their organizational characteristics that can handle uncertainties in the contingencies to achieve high performance and avoid any losses due to misfit when contingencies changes. The contingencies represent any variable that moderates the effect of an organizational characteristic of its performance. Researchers such Blanton et al. (1992) used the components: structure, environment, strategies and environment as illustrated in figure 2, to explain how an organization would require its structures to create strategies to improve the organization's economic stance in the market, thus ensuring the organization (performance) creates a profit.

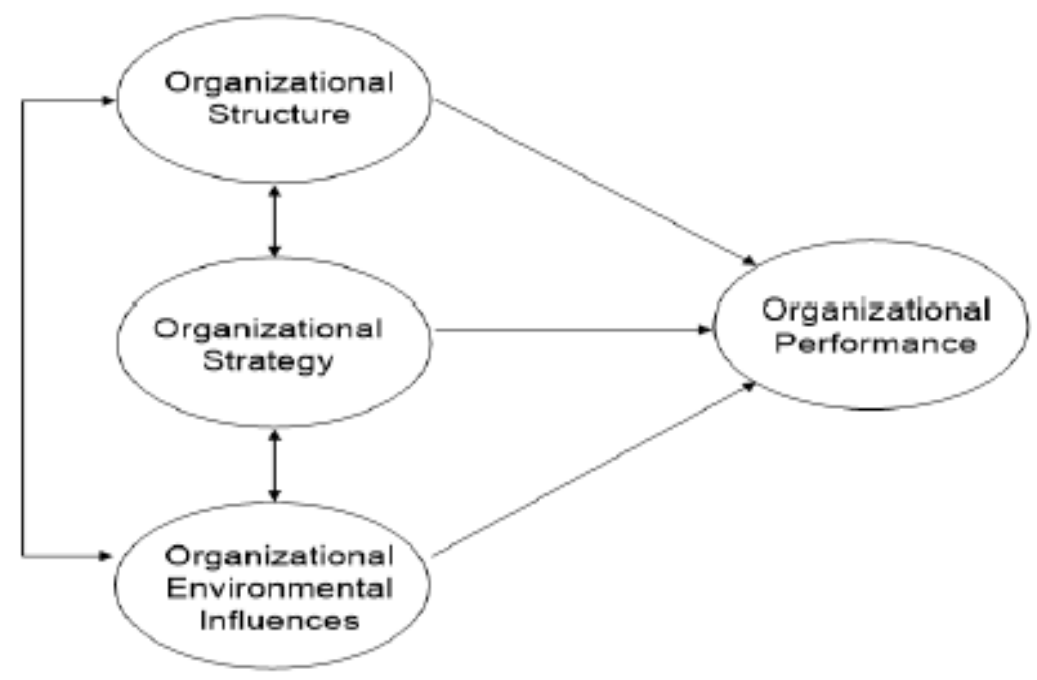

Figure 2. Contingency Theory (Blanton et al., 1992)

The contingency components are briefly explained as follows:

- An environment is a place that allows its employees to work in favourable conditions. Employees, embracing the same vision, should be able to complete a task easily by freely accessing various procedures and processes.

- The structure is the foundation of each organization that explains how tasks can be shared or how to delegate responsibilities in different departments to maintain the processes within the organization. It also allows decision making to sustain workflow.

- The strategy is the core of the organization. It directs the functions of the organization in the long term. It allows the organization to be sustainable towards its competitors.

- Performance is defined as the past, present and future accomplishment of a given organizational task against pre-set standards of accuracy, completeness or whether cloud computing delivers value or not.

\section{BACKGROUND TO THE RESEARCH PROBLEM}

This section discusses the knowledge gaps and problem statement.

\subsection{Knowledge Gaps}

The knowledge gaps are discussed into theoretical knowledge gaps, methodological knowledge gaps, context and study location. 


\subsubsection{Theoretical Gaps}

The review of literature on cloud computing has highlighted knowledge gaps that need to be addressed by this study. Previous studies on cloud computing were reviewed and the technology-organization-environment (Tornatzky, Fleischer and Chakrabarti, 1990)(TOE) is mostly used as a research lens. The TOE framework is an organisation level theory that explains the three elements that influence technology adoption decisions. The TOE framework elements are the organisational context, technological context and environmental context. The literature seems to be consistent of the three factors suggested by the TOE framework. Empirical research that combines stakeholder theory and contingency theory has not yet researched in the context of the South African information technology professionals. Therefore, this study is underpinned by stakeholder theory and contingency theory as the research lens that will bridge the theoretical knowledge gap.

\subsubsection{Methodological Gaps}

Previous studies on cloud computing has highlighted knowledge gaps with regard to methodology. The studies reviewed, used the survey methods as a research strategy. The methodological findings indicate that, there are fewer qualitative studies that have contributed to the understanding of cloud computing. The case study method is considered the most appropriate and viable for its in-depth approach. According to Yin (2016) a case study research strategy allows the researcher a deep understand of a phenomenon. In the context of this study, the study used the case study as research strategy.

\subsubsection{Context and Study Location}

Organizations in South Arica have seen an exponential increase in the use of information technology, specifically the use of the internet. The use of information technology in the organizations has increased the budget expenditure on IT infrastructure, software licensing, support, and maintenance costs. Considering these challenges, there is a need for cost-effective alternative technology. Cloud computing can be seen as an alternative technology. In the context of this study, the practical gap is bridged by developing a conceptual framework that combined key stakeholders' views on cloud computing. The stakeholders included executives, senior managers, middle managers, experts, and the users of cloud computing in their private capacity. South Africa as the location of the study. South Africa or the republic of South Africa is situated in the southern country in Africa. The paper conceptualizes a strategic cloud computing framework in the context of South African information technology professionals

\subsection{Problem Statement}

Against the aforementioned literature review, it is evident that the adoption and use of cloud computing in the context of South African is necessary for the organizations to realise maximum value from cloud computing investments and to improve operational efficiency. How cloud computing may be strategically used or adopted has not been adequately addressed in the literature. The following observations further supported that, there are still some knowledge gaps in realising the value of cloud computing in the South African context.

- Lack of literature that address the cloud computing adoption and use in the context in the context of South African information technology professionals.

- Lack of a theoretical framework that describes the drivers of cloud computing for different stakeholders.

- The conceptual framework that describes the adoption and use of cloud computing in the South African context.

Hence, this study will bridge the identified knowledge gap by developing a strategic cloud computing framework for the adoption and use of cloud computing in the South African context. This study is set out to determine how cloud computing could be strategically adopted and use sensitively to the South African context. The next section discusses the theoretical framework. 


\section{RESEARCH METHODS}

This section discusses the research methodology that will be followed to develop a strategic cloud computing framework in the context of South African information technology professionals. This study attempts to obtain deep, rich data on cloud computing adoption and use from individuals. This study follows an interpretivism paradigm. Interpretive researchers believe that the reality to consists of people's subjective experiences of the external world (Saunders, Lewis and Thornhill, 2016). The interpretivism paradigm, gives the researcher the best way to understand the phenomena of cloud computing in South Africa context with the views and experiences of South African information technology professionals. This study used a qualitative research method. The reason for choosing the qualitative research method is to collect primary data from individuals with working experience and knowledge of cloud computing. This will help in understanding of how should cloud computing be strategically adopted and used sensitive to the South African context. The nature of this study is interpretive and research approach is qualitative research approach that is inductive in nature.

\subsection{Research Strategy}

The case study is a preferred research strategy, given the interpretive position and the nature of research questions. According to Yin (2016) a case study research strategy allows the researcher a deep understand of a phenomenon. This study uses a case study strategy. A case study approach is selected to obtain data from managers, professional, cloud experts, consultants, and user through semi-structured interviews. The reasons for conducting interviews is to obtain rich information about how cloud computing can be strategically adopted and user in the context of South African information technology professionals.

\subsection{Research Design}

\subsubsection{Participants}

This study attempts to obtain deep rich data on cloud computing adoption and use from individuals. The adoption and use of cloud computing will be understood through interviews. The study anticipates conducting interviews with IT professionals, including senior managers, middle managers, cloud experts, consultants, and users of cloud computing who have working experience and knowledge of cloud computing adoption and use, including those who take decisions about cloud computing technology

\subsubsection{Data Collection Techniques}

This study is a qualitative study and the following data collection techniques will be followed to collect empirical evidence for the study.

- Interviews: for this study, semi-structured interviews will be used to collect primary data. This study is set out to determine how cloud computing could be strategically adopted or used sensitively to the South African context. The face to face interviews will be conducted with individuals.

- Observations: for this study, the researcher as a participant-observer will be observing how the participant's behavior when answering questions. The observations will support the outcomes of the interviews

\section{STRATEGIC CLOUD COMPUTING FRAMEWORK}

This section discusses the conceptual research framework. The framework is developed from stakeholder theory by Freeman (1984), contingency theory (Blanton, Watson, \& Moody, 1992) and technology-organization-environment (Tornatzky, Fleischer and Chakrabarti, 1990) which was used as the research lenses. The high-level view of the conceptual framework is made of environmental, stakeholder, contingencies, organizational and technological. Figure 3 is the proposed strategic cloud framework. 


\section{STRATEGIC CLOUD COMPUTING FRAMWORK FOR IT PROFESSIONALS}

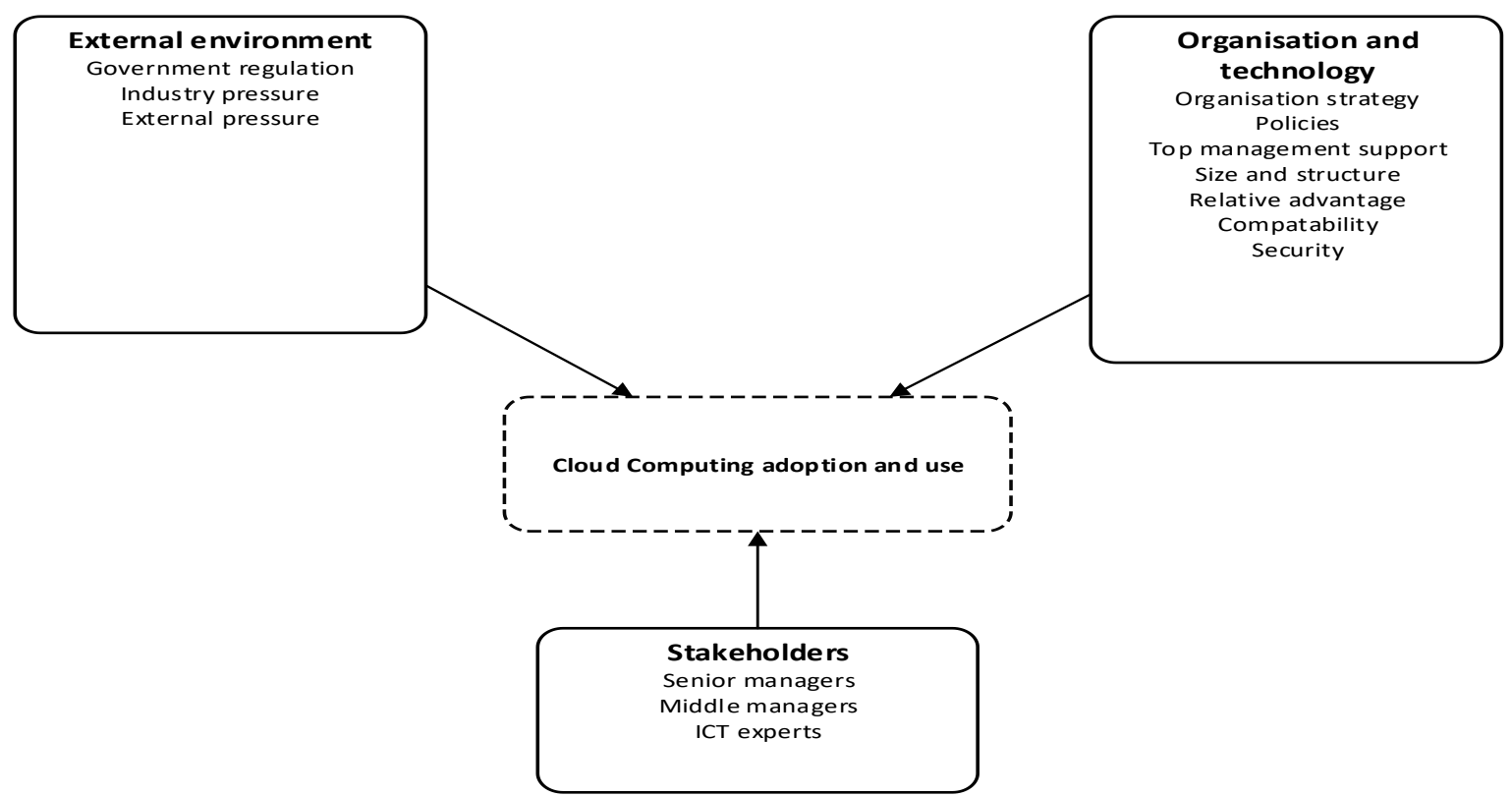

Figure 3. Strategic Cloud Computing Framework (Researcher)

The framework components are briefly explained

1. External environment - the environmental factors look at how the organization operates. For this study, the conceptual framework included the following environmental constructs:

- Government regulation - government regulation refers to the support given by a government authority to encourage the adoption of cloud computing within the South African context.

- Competitive pressure - competitive pressure refers to the pressure felt by the organizations from industry competitors.

- $\quad$ Trade partner pressure - trade partner pressure refers to the pressure felt by the organization from business partners with whom the business is conducted.

2. Stakeholders - in this study the conceptual framework, stakeholders will include the following stakeholders, senior managers/executives, middle managers, ICT experts, and consultants.

3. Contingencies - for this study the conceptual framework, contingencies for analyzing cloud computing are as follows:

- Size and structure - size refers to the size of an organization in terms of number of employees and the organization structure.

- Strategy - strategy is defined as the direction and scope of an organization over the longterm required to achieve organizational goals and objectives.

4. Organization - for this study, the conceptual framework will use the following organizational constructs:

- Policies - organization policies that may enable or hinder the adoption and use of cloud computing.

- Management support - refers to top management support for the adoption of cloud computing

- Relative advantage - refers to the benefits and advantages that can be gained by using cloud computing over the traditional way 
5. Technological factors - for this study, the conceptual framework will use the following technological constructs:

- Compatibility - refers to the degree in which existing infrastructure can be used with cloud computing technology.

- Security - refers to how secure is the cloud computing environment.

\section{CONCLUSION}

The paper showed how cloud computing could be strategically adopted and use sensitively to the South African context. The paper conceptualizes a strategic cloud computing framework for the adoption and use of cloud computing in the South African information technology professional's context. To help understand the adoption and use of cloud computing in the context of South African information technology professionals, the stakeholder theory (Freeman, 1984) and contingency theory (Blanton, Watson, \& Moody, 1992) are used as research lenses. The paper envisages that a strategic cloud computing framework will help to position the cloud computing adoption and use sensitively to South African organizations strategically, to address the needs of different stakeholders. Furthermore, the framework would assist to strategically adopt and use cloud computing in a uniformed and coordinated manner.

\section{ACKNOWLEDGEMENT}

The author would like to Prof Ray Kekwaletswe for his support during this research and Unisa Graduate School of Business Leadership (SBL).

\section{REFERENCES}

Blanton, J. E., Watson, H. J. and Moody, J. (1992) 'Toward a Better Understanding of Information Technology Organization: A Comparative Case Study', MIS Quarterly, 16(4), p. 531. doi: 10.2307/249735.

Chang, V., Walters, R. J. and Wills, G. (2011) 'Review of Cloud Computing and Existing Frameworks for Cloud Adoption', IEEE Security \& Privacy, (2014), p. 35. doi: DOI: 10.4018/978-1-4666-8210-8.ch001.

Clarkson, M. B. . (1995) 'A Stakeholder Framework for Analysing and Evaluating Corporate Social Performance', Academy of Management Review, 20(1), pp. 92-117. doi: 10.5465/AMR.1995.9503271994.

Freeman, R. E. (1984) Strategic Management: A Stakeholder Approach, Analysis. doi: 10.2139/ssrn.263511.

Hayes, B. (2008) 'Cloud computing', Communications of the ACM, 51(7), p. 9. doi: 10.1145/1364782.1364786.

Mell, P., Grance, T. and Grance, T. (2011) 'The NIST Definition of Cloud Computing Recommendations of the National Institute of Standards and Technology', National Institute of Standards and Technology, Information Technology Laboratory, 145, p. 7. doi: 10.1136/emj.2010.096966.

Saunders, M., Lewis, P. and Thornhill, A. (2016) 'Research Methods for Business Students', in Research methods for business students, p. 649. doi: 10.1017/CBO9781107415324.004.

Tornatzky, L. G., Fleischer, M. and Chakrabarti, A. K. (1990) The processes of technological innovation. Lexington Books. Available at: https://openlibrary.org/books/OL2207473M/The_processes_of_technological_innovation (Accessed: 30 March 2018).

Varia, J. (2010) 'Migrating your existing applications to the AWS cloud', A Phase Driven Approach to Cloud Migration.

Yang, H. and Tate, M. (2009) 'Where are we at with Cloud Computing?: A Descriptive Literature Review', in Australasian Conference on Information Systems. doi: 10.17705/1CAIS.03102.

Yin, R. K. (2016) Qualitative research from start to finish, Qualitative research from start to finish. doi: 10.1007/s 13398014-0173-7.2. 